\title{
A combined fMRI and DTI examination of functional language lateralization and arcuate fasciculus structure: Effects of degree versus direction of hand preference
}

\section{Citation}

Propper, Ruth E., Lauren J. O'Donnell, Stephen Whalen, Yanmei Tie, Isaiah H. Norton, Ralph 0. Suarez, Lilla Zollei, Alireza Radmanesh, and Alexandra J. Golby. 2010. “A Combined fMRI and DTI Examination of Functional Language Lateralization and Arcuate Fasciculus Structure: Effects of Degree Versus Direction of Hand Preference." Brain and Cognition 73 (2) (July): 85-92. doi:10.1016/j.bandc.2010.03.004.

\section{Published Version}

10.1016/j.bandc.2010.03.004

\section{Permanent link}

http://nrs.harvard.edu/urn-3:HUL.InstRepos:34178448

\section{Terms of Use}

This article was downloaded from Harvard University's DASH repository, and is made available under the terms and conditions applicable to Other Posted Material, as set forth at http:// nrs.harvard.edu/urn-3:HUL.InstRepos:dash.current.terms-of-use\#LAA

\section{Share Your Story}

The Harvard community has made this article openly available.

Please share how this access benefits you. Submit a story.

\section{Accessibility}




\title{
A Combined fMRI and DTI Examination of Functional Language Lateralization and Arcuate Fasciculus Structure: Effects of Degree Versus Direction of Hand Preference
}

\author{
Ruth E. Propper ${ }^{1,3}$, Lauren J. O'Donnell ${ }^{1}$, Stephen Whalen ${ }^{1}$, Yanmei Tie ${ }^{1}$, Isaiah H. \\ Norton ${ }^{1}$, Ralph 0. Suarez ${ }^{1}$, Lilla Zollei ${ }^{2}$, Alireza Radmanesh ${ }^{1}$, and Alexandra J. Golby ${ }^{1}$ \\ ${ }^{1}$ Golby Neurosurgical Brain Mapping Laboratory, Departments of Neurosurgery and Radiology, \\ Brigham and Women's Hospital, Harvard Medical School, Boston, MA
}

${ }^{2}$ A. A. Martinos Center, Massachusetts General Hospital, Boston, MA

${ }^{3}$ Merrimack College, Psychology Department, North Andover, MA

\begin{abstract}
The present study examined the relationship between hand preference degree and direction, functional language lateralization in Broca's and Wernicke's areas, and structural measures of the arcuate fasciculus. Results revealed an effect of degree of hand preference on arcuate fasciculus structure, such that consistently-handed individuals, regardless of the direction of hand preference, demonstrated the most asymmetric arcuate fasciculus, with larger left versus right arcuate, as measured by DTI. Functional language lateralization in Wernicke's area, measured via fMRI, was related to arcuate fasciculus volume in consistent-left-handers only, and only in people who were not right hemisphere lateralized for language; given the small sample size for this finding, future investigation is warranted. Results suggest handedness degree may be an important variable to investigate in the context of neuroanatomical asymmetries.
\end{abstract}

\section{Keywords}

Handedness; language; arcuate fasciculus; FMRI; DTI

There are well-known hemispheric asymmetries in human neuroanatomy and in cognitive processing. Investigations of patient and non-patient populations have repeatedly demonstrated that the left and right hemispheres (LHem and RHem) differ in their structures (e.g.: in the size, location, and/or shape of different areas) and in their information processing abilities (see Cabeza \& Nyberg, 2000; Gazzaniga, 2000; Hellige, 2001).

Some of the most frequently investigated hemispheric asymmetries involve language. Functionally, in the majority of humans, speech production and language comprehension are primarily LHem phenomena (e.g., Cabeza \& Nyberg 2000; Knecht et al., 2000a;

\footnotetext{
(c) 2009 Elsevier Inc. All rights reserved.

Corresponding author: Ruth E. Propper, Merrimack College, Psychology Department, 315 Turnpike Street, North Andover, Massachusetts, 01845; Phone: (978) 837-5000 x 4369; ruth.propper@ merrimack.edu; Fax: (978) 837-5069.

Publisher's Disclaimer: This is a PDF file of an unedited manuscript that has been accepted for publication. As a service to our customers we are providing this early version of the manuscript. The manuscript will undergo copyediting, typesetting, and review of the resulting proof before it is published in its final citable form. Please note that during the production process errors may be discovered which could affect the content, and all legal disclaimers that apply to the journal pertain.
} 
Papathanassiou et al., 2000; see also Hellige, 2001). Similarly, and again in the majority of the population, neuroanatomic structures known to be involved in language functions are larger or more pronounced in the LHem, compared to the RHem. For example, the planum temporale, the pars opercularis, and the pars triangularis are larger, and the sylvian fissure longer, in the LHem relative to the RHem (Dorsaint-Pierre et al., 2006; Foundas, Leonard, Gilmore, Fennell, \& Heilman, 1996; Shapleske et al., 1999; see Hellige, 2001 for extensive review).

Despite the clear LHem bias in the processing of language information and in the neuroanatomical structures involved in language, the relationship between a given neuroanatomical structure and functional language lateralization remains unclear. For example, do any particular neuroanatomical structures reliably predict functional language lateralization? From a theoretical perspective, looking at structural (neuroanatomical) markers for functional language lateralization (i.e.: language processing) may offer answers to some of the questions surrounding cerebral asymmetries generally. From a practical perspective, such investigations could offer a complementary method for determining functional language lateralization in pre-surgical settings. It should be noted that although candidate structural markers for hemispheric asymmetries in language processes have been proposed, for example the planum temporale (considered part of 'Wernicke's area'; see Shapleske et al., 1999) and the pars triangularis (considered part of 'Broca's area'; see Foundas, Leonard, Gilmore, Fennell, \& Heilman, 1996; Dorsaint-Pierre et al., 2006), as yet no definitive neuroanatomical marker has been determined for functional language lateralization.

Given the extensive nature of the network of structures thought to be involved in language processes, functional language lateralization is likely the result of asymmetries in both cortical areas and in white matter tracts. However, it is only relatively recently that technologies exist allowing for in vivo examination of white matter tracts in neurologically healthy individuals. The relatively new technology of diffusion tensor magnetic resonance imaging (DTI) measures the three-dimensional pattern of diffusion of water molecules (Pierpaoli, Jezzard, Basser, Barnett, \& Di Chiro, 1996) and can be used to estimate the trajectories of large white matter tracts such as the arcuate fasciculus via a process called tractography (Basser, Pajevic, Pierpaoli, Duda, \& Aldroubi, 2000). The arcuate fasciculus (AF) is thought to be an important connection between Broca's and Wernicke's areas (e.g.: Dronkers \& Larsen, 2001), and consistent with its role in language function, the AF has been shown to be larger in the left, relative to the right, hemisphere using DTI methodologies, at least in right-handers (e.g.: Nucifora, Verma, Melhem, Gur, \& Gur, 2005; Hagmann et al., 2006; Parker et al., 2006).

Although the AF is typically larger in the LHem, and functional language lateralization more LHem lateralized in Broca's and Wernicke's areas, investigations of either causal or correlational relationships between asymmetries in neuroanatomy and asymmetries in language processing have been hampered by at least two issues: i) in the vast majority of neurologically intact humans, language is a left hemisphere phenomenon (Knecht et al, 2000b); and ii) although there are individual differences in the extent of language lateralization even when language is lateralized to the left hemisphere, most research has not taken advantage of this heterogeneity, but has instead excluded those participants who are more likely to have atypical language lateralization (i.e. non-right-handers, see for example Knecht et al, 2000b) and then assumed that these remaining right-handed subjects are simply 'left hemisphere lateralized' for language.

Individual differences in hand preference have been used to indicate the more or less likely presence of 'atypical' language organization, and to investigate the neuroanatomical substrates responsible for hemispheric asymmetries in language processing (e.g.: Foundas, Leonard, Gilmore, Fennell, \& Heilman, 1996; Moffat, Hampson, \& Lee, 1998; Powell et al., 2006; Vernooij et al., 2007). Non-right-handedness is associated with increased incidence of 'atypical' 
hemispheric (e.g., right hemisphere or bilateral) language processing (Knecht et al., 2000b; Khedr, Hamed, Said, \& Basahi, 2002; Basic et al., 2004; Szaflarski et al., 2002), as well as with 'atypical' neuroanatomic asymmetries in language related areas, such as in Broca's (e.g.: Foundas, Eure, Luevano, \& Weinberger, 1998) and in Wernicke's areas (e. g.: Shapleske, Rossell, Woodruff, \& David, 1999). Interestingly, it has been suggested that human hand preference may be sub-served by the same genetic (e.g.: McManus \& Bryden, 1992; Laland, Kumm, van Horn, \& Feldman, 1995) and/or evolutionary (e.g.: Corballis, 2003) mechanisms as those which are responsible for lateralization of language, further indicating that individual differences in hand preference are a good 'marker' for individual differences in cerebral asymmetries in language processing and/or neuroanatomy.

To our knowledge, only one study has examined the relationship between hand preference, DTI measured asymmetry of the AF, and functional lateralization of language processing (Vernooij et al., 2007). Using DTI and functional magnetic resonance imaging (fMRI), Vernooij et al. reported a LHem bias in relative "fiber density" (a DTI tractography-based measure) of the AF regardless of direction (left- versus right-handers) of hand preference. There was no relationship found between functional language lateralization in Broca's area and AF asymmetry. In right-handers only, increasing LHem lateralization in language processing in Wernicke's (but not in Broca's) area was correlated with increasing LHem fiber density of the AF. These results suggest that AF asymmetry is related to functional lateralization of language in Wernicke's area but not in Broca's area, and only in right-handers.

Vernooij et al.'s (2007) findings of a) larger AF in the LHem regardless of handedness and b) a null relationship between functional language lateralization in Broca's area and AF structural asymmetry, are unexpected in light of frequent findings of i) reduced or reversed asymmetries in neuroanatomical structures in non-right-handers and; ii) positive relationships between hemispheric asymmetries in neuroanatomy and in language processes in Broca's area (See Hellige, 2001 for review). We suggest here that the null results of Vernooij et al.(2007) may have stemmed, in part, from the particular handedness categorizations used. Specifically, Vernooij et al., confounded direction (left versus right) with degree (consistent versus inconsistent) of hand preference, possibly obscuring handedness relationships to AF structure, as well as relationships between AF neuroanatomy and functional language lateralization. Vernooij et al. categorized both consistent-left-handers (CLH) and inconsistent-handers (ICH) as 'left-handed', although interestingly the majority of the non-right-handed group was in fact $\mathrm{CLH}(\mathrm{CLH} \mathrm{n}=10, \mathrm{ICH}=3$, see Methods, below). Given that research indicates that in many measures of behavior and physiology, the CLH and CRH are more similar to each other than either is to the ICH, with the latter group most likely to demonstrate bihemispheric language (e.g.: Barnett \& Corballis, 2002; Christman 1995; Khedr et al., 2001; Niebauer, Aselage, \& Schutte, 2002; Propper, Christman, \& Phaneuf, 2005), inclusion of CLH and ICH in one group may decrease the likelihood of finding handedness effects on brain structures and functions. It may be that $\mathrm{AF}$ structure, and its relationship with functional language lateralization, varies as a function of degree, rather than direction, of hand preference.

Using DTI for arcuate fasciculus identification, in conjunction with fMRI for determination of functional language lateralization, the present study examined the relationship between language lateralization and arcuate fasciculus asymmetry as a function of both direction and degree of hand preference. To our knowledge this is the first study to separately analyze the effects of degree and direction of hand preference on arcuate fasciculus structure in each hemisphere using variables from quantitative DTI tractography. As stated, studies examining populations with a range of neuroanatomic and cognitive asymmetries are useful for determining structure-function relationships. We measured the AF quantities of length (AFL) and volume (AFV). 


\section{Methods}

\section{Participants}

The protocol was approved by the Partner's Institutional Review Board, and all subjects gave written informed consent. Participants had no history of neurological problems, psychiatric illness, or head trauma. Subjects were recruited via advertisement on local college campuses and were paid $\$ 50.00$ for their participation. Twenty-six individuals participated; 9 men and 17 women (age $M=28.54$ years, $S D=9.19$ ). One female was eliminated from analyses for failing to complete the protocol. See below (and Table 1) for discussion of handedness group determination and number of subjects per handedness group.

\section{Hand Preference Calculation}

Handedness was determined via score on the Edinburgh Handedness Inventory (EHI; Oldfield, 1971), which lists 10 activities that participants rate as always, usually, or have no preference of performing with one hand versus the other. Scoring for answers of 'always' are +10 for 'righthanded' and -10 for 'left-handed'; 'usually' is scored $+5 /-5$, and 'no preference is scored as ' 0 '. Thus, scores can range, in multiples of 5 , from -100 , indicating perfect consistent left-hand preference, to +100 , indicating perfect consistent right-hand preference. In order to define handedness groups, the absolute value of the EHI was calculated for our sample, and the absolute median (median $=75.00$ ) was used (e.g.: Brunye, Mahoney, Augustyn, \& Taylor, 2009; Lyle, Logan, \& Roediger, 2008; Propper, Christman, \& Phaneuf, 2005) as the cut-off for handedness groups after returning the positive versus negative sign to each individual: $\mathrm{CRH}$ (+75 and above) and CLH ( -75 and below). Individuals scoring between positive or negative 70 were categorized as ICH. The number of participants in each group was as follows: $\mathrm{CRH}$ $n=8$, CLH $n=7$, ICH $n=10$. See Table 1.

\section{Imaging data acquisition}

All images were acquired using a General Electric (Milwaukee, WI) 3T Signa scanner with Excite 14.0. Whole brain T1-weighted axial 3D-SPGR (spoiled gradient recalled) structural images were acquired using an 8-channel head coil and ASSET (Array Spatial Sensitivity Encoding Technique, i.e., parallel imaging) $(\mathrm{TR}=7500 \mathrm{~ms}$; TE=30 ms; Flip Angle $=20^{\circ}$; matrix $=256 \times 256 ; 176$ slices; voxel size $=1 \times 1 \times 1 \mathrm{~mm}^{3}$ ) for subsequent overlay of functional activations.

\section{Functional MRI Acquisition and Analysis}

Image acquisition-Whole-brain functional images were acquired using a quadrature head coil with a T2*-weighted echo-planar imaging (EPI) sequence sensitive to the blood-oxygenlevel dependent (BOLD) signal (TR=2000 ms; TE=40 ms; matrix=64 × 64; FOV=24 cm; 27 ascending interleaved axial slices with $0 \mathrm{~mm}$ gap, voxel size $=3.75 \times 3.75 \times 5 \mathrm{~mm}^{3}$ ). The coil was changed from a 4 to an 8 channel coil between structural and functional scanning.

Behavioral paradigm-A silent, blocked-design, antonym-generation task was used to examine functional language lateralization. This task was chosen because it usually results in activations in the frontal and temporal language areas. This task consisted of six 20 -second activation blocks, interleaved with six 20 -second blocks of rest (fixation to crosshairs presented in center of screen). Each stimulus word was shown for two seconds in the center of the screen, with an inter-stimulus-interval of $500 \mathrm{~ms}$; eight words were shown in each block. Participants were asked to think of a word having the opposite meaning as the presented word. 
Stimuli were presented using a PC laptop (Dell, Inc., Austin, TX), running the E-prime software package (Psychology Software Tools, Pittsburgh, PA) and projected through MR-compatible goggles (Resonance Technology, Northridge, CA).

fMRI analysis and generation of functional ROIs-We used Statistical Parametric Mapping software package (SPM2; Wellcome Department of Imaging Neuroscience, London, UK) to pre-process and analyze the fMRI data. Following image reconstruction, functional images were motion-corrected, spatially normalized to Montreal Neurological Institute (MNI) template, and smoothed with an $8 \mathrm{~mm}$ full-width-half-maximum (FWHM) Gaussian kernel. First-level general linear model (GLM; Friston et al., 1995) analysis was performed on each subject's data. An estimate of the canonical hemodynamic response function (HRF) was used as the basis function, and only task conditions were explicitly modeled. Then a second-level random-effect (RFX) analysis (one-sample t-test) was performed on the contrast images derived from the first-level analyses, separately on the three defined groups (CRH, CLH, and $\mathrm{ICH})$. The group $\mathrm{t}$-maps were thresholded at $\mathrm{p}<0.05$, FWE corrected $(\mathrm{t}=6.14, \mathrm{df}=24)$.

Functional ROIs for putative language areas were generated by masking the thresholded group t-map with atlas-based Broadman's areas 44 and 45 in the left inferior frontal gyrus (IFG) for Broca's ROI; and masking with the combination of left superior temporal gyrus (STG), middle temporal gyrus (MTG), supramarginal gyrus (SMG), and angular gyrus (AG) for Wernicke's ROI. Homologues of the ROIs were generated by mirror projection to the right hemisphere (Jansen, et al., 2006). Atlas-based structural masks were generated using WFU PickAtlas software (Department of Radiologic Sciences, Wake Forest University, Winston-Salem, NC, USA).

Laterality Index (LI) calculation-For individual subject, laterality indices (LIs) were calculated based on the results of single subject first-level GLM analysis. A thresholdindependent methodology for LI calculation was applied (Branco et al., 2006; Suarez et al, 2009). Briefly, histograms were generated that tabulated the total number of voxels having positive $\mathrm{T}$ scores within the functional ROIs, and then multiplied by a linear weighting function. Finally a numerical integration of the areas under the entire weighted distributions for each hemisphere was used in equation LI = (LHA RHA $) /(\mathrm{LHA}+$ RHA $)$, where LHA represents the area under the weighted distribution curve for the left hemisphere and RHA represents the area under the weighted distribution curve for the right hemisphere. LIs having positive magnitude denote left-asymmetry, while negative LIs represent right-asymmetry. Note that asymmetry scores can vary along a continuum from +1.00 (complete LHem activation) to -1.00 (complete RHem activation).

\section{DTI acquisition and analysis}

For DTI, echo-planar images were acquired using an 8-channel head coil and ASSET matrix $=128 \times 128 ; \mathrm{FOV}=25.6 \mathrm{~cm}$; Phase FOV $=1.0$; slice thickness $=2.6 \mathrm{~mm} ; \mathrm{B}$ value $=1000 \mathrm{~s} /$ $\mathrm{mm} 2$; 55 DWI gradients and 5 baseline T2 images; voxel size $=2 \times 2 \times 2.6 \mathrm{~mm}$.

DTI tractography is a method that estimates white matter tract trajectories by repeatedly stepping in the direction of maximal water diffusion (Basser, Pajevic, Pierpaoli, Duda, \& Aldroubi, 2000). Whole brain tractography was generated by seeding trajectories ("fibers") on a $2 \mathrm{~mm}$ grid throughout the entire white matter of each subject,starting where Westin's linear anisotropy measure (Westin et al., 2002) was over 0.3 and terminating where it was below 0.15 , using Runge-Kutta order two integration. The linear anisotropy measure was chosen for seeding because the single tensor streamline tractography works well only in regions of "cigar shapes" or linear anisotropy. The tractography package used was 3D Slicer (www.slicer.org). DTI tractography was normalized to a common coordinate system created by congealing (an 
entropy-based unbiased group registration method; Zöllei et al., 2005) of all subjects' fractional anisotropy images. The normalization step controlled for differences in overall brain size across subjects that could otherwise affect the structural dependent measures (see below). Note this normalization step was applied for purposes of DTI structural measurements and was not used in the (separate) fMRI analysis. The tractography was automatically segmented into 400 clusters using the high-dimensional atlas method (O'Donnell \& Westin, 2007; O'Donnell, Westin, \& Golby, 2009) that employs simultaneous spectral clustering in all subjects to identify common white matter structures. All structures were visualized and 3 clusters that formed curved bundles connecting frontal, parietal, and temporal lobes were identified as representative of the AF by the second and senior authors (LJO, AJG). Clusters were selected while viewing all bundles in several randomly selected subjects, then clusters were confirmed by viewing all subjects' tractography within the selected bundles.

AF fibers were analyzed in each hemisphere to produce two quantitative measures: arcuate fasciculus volume (AFV) and arcuate fasciculus length (AFL). AFV was defined as the volume of $1 \mathrm{~mm}$ cubic voxels occupied by the fibers in each subject. AFL was defined as the average length of the fibers in each subject. The voxel size was chosen to simplify the volumetric calculations (because counting $1 \mathrm{~mm}$ cubed voxels gives the volume directly with no need to account for voxel volume). In addition, a smaller voxel size (relative to the voxel size of the DTI scan) was chosen to more accurately measure the volume of the AF, because the tractography operates with subvoxel precision. Laterality indices (LIs; calculated via the formula $((\mathrm{LHem}-\mathrm{RHem}) /(\mathrm{LHem}+\mathrm{RHem}))$ were also calculated for both of the DTI dependent variables. LIs having positive magnitude denote left-asymmetry, while negative LIs represent right-asymmetry. Note that asymmetry scores can vary along a continuum from +1.00 (complete LHem lateralization) to -1.00 (complete RHem lateralization).

\section{Statistical analyses}

In order to examine handedness and its relationship with the fMRI language lateralization dependent variables (i.e.: number of activated voxels in Broca's and Wernicke's areas in each hemisphere) and the DTI dependent variables (AFV and AFL each hemisphere), four mixed ANOVAs (Between subject: Handedness: CLH, CRH, and ICH; Within subject: Hemisphere: LHem vs RHem) were conducted on fMRI activation in Broca's and Wernicke's areas, and DTI measures of AFV and AFL. Because our hypotheses concerned a priori differences between groups in asymmetry, paired t-tests, Bonferroni corrected $(\alpha=02$ [. .05 divided by 3 comparisons per measure], were conducted on the dependent measures in the left and right hemispheres as a function of Handedness group. 1-Way ANOVAs examining Handedness effects on laterality indices were also performed.

Given our small sample sizes, and in accordance with the Publication Manual of the American Psychological Association (APA, 2001), we also included Cohen's $d$ as a measure of effect size. Cohen's $d$ can be used to indicate whether non-significant differences between groups reflect low power, the result of small sample sizes and/or large variability, and are non-trivial. Effect sizes greater than or equal to .80 are considered large, while those less than .20 are considered small (see Valentine \& Cooper, 2003).

In order to examine the relationship between functional language lateralization and structural measures of the AF, laterality indices for the fMRI variables of activation in Broca's and Wernicke's areas were each correlated with laterality indices for each of the DTI measures for each handedness group. 


\section{Results}

\section{Handedness Scores}

Handedness scores ranged from -100 to +100 (EHI $M=4.20, S D=75.01$ ). The handedness groups (CLH, CRH, and ICH) did not differ in age (ANOVA; $p>.05 ; M=28.68, S D=9.35$ ) or in gender composition (Chi Square, $p>.05$; The number of participants in each group was as follows: $\mathrm{CRH} n=8, \mathrm{CLH} n=7$, ICH $n=10$. See Table 1 for number of subjects, gender, and age compositions per handedness groups).

\section{ANOVAs}

FMRI Activation-ANOVAs (3: Handedness: CRH, ICH, CLH) $\times(2$ : Hemisphere: LHem versus RHem) revealed higher activation in LHem Broca's $(\mathrm{f}(1,2)=29.23, p<.001)$ and LHem Wernicke's $(\mathrm{f}(1,2)=19.80, p<.001)$ areas than those in the RHem. Planned pair-wise comparisons revealed different relationships between the LHem and RHem as a function of handedness group. Activation in Broca's area was greater in LHem compared to RHem in CRH $(\mathrm{t}(7)=4.12, p<.02, d=1.45)$ and in ICH $(\mathrm{t}(9)=5.06, p<.02, d=2.06)$, but not in CLH $(p=.19, d=$. 97) (See Figure 1). Activation in Wernicke's area was greater in LHem compared to RHem in CRH $(\mathrm{t}(7)=4.63, p<.02, d=1.01)$ and in ICH $(\mathrm{t}(9)=2.93, p=.02, d=.79)$, but not in CLH $(p=.16$, Bonferroni corrected, $d=1.04$ )(See Figure 2). No group differences in laterality indices were observed. See Table 2.

DTI Measures-Mixed-ANOVAs (3: Handedness: CRH, CLR, ICH) $\times(2$ : Hemisphere: LHem versus RHem) revealed greater LHem AFV compared with RHem AFV $(\mathrm{f}(1,2)=9.79$, $p<.01$; See Figure 3$)$ and greater LHem AFL compared to RHem AFL $(\mathrm{f}(1,2)=4.32, p<.05$; See Figure 4). Planned pair-wise comparisons revealed strong trends for different relationships between the LHem and RHem as a function of handedness group. LHem AFV was greater than RHem AFV ( $\mathrm{t}(7)=2.72, p<.03, d=1.12)$ in $\mathrm{CRH}$, but not significant in either other group (CLH $p=.11, d=1.06$, ICH $p=.78, d=.07)$. No group differences in laterality indices were observed. See Table 2. See Figures 5a, 5b, and 5c for representative tracts of AF structure from each Handedness group. See Figures $6 a, 6 b$, and $6 c$ for fMRI and DTI images as a function of handedness group.

\section{Correlations}

It should be noted that correlations were performed between fMRI LI and DTI LI measures wherein the values of interest were able to be calculated for at least one hemisphere. For two participants (both ICH), AFV and AFL could not be calculated for both hemispheres (We would like to point out that normal variation in the AF results in an inability to track this structure in both hemispheres in up to $62.5 \%$ of individuals [Catani et al., 2007]. It is therefore expected that in our sample there would be an inability to trace the AF in some subjects. All participants' tractography and clustering results were visually inspected for errors). Note that individuals in whom there was an inability to tract the AF were given a score of ' 0 ' in the other analyses. Thus, for the AFV and AFL analyses, ICH $n=8$, while for the other analyses, these two participants were included with scores of ' 0 '. This was done to enable us to examine the possibility that handedness may be a factor that can account for some of the variability in tracking the AF.

Broca's Area-No correlations between LI in Broca's area and either DTI LI measure as a function of handedness neared significance ( $p>30$ for all comparisons).

Wernicke's Area-No correlations between LI in Wernicke's area and either LI DTI measure as a function of handedness reached significance ( $p>.10$ for all comparisons). 
Because right hemisphere only activation in Broca's and Wernicke's areas is unusual regardless of handedness (e.g.; Knecht et al., 2000b), and may indicate anomalous cerebral organization beyond that involved in language areas, we performed identical correlations excluding four individuals in whom language was RHem lateralized: in Broca's area (1 CLH and $1 \mathrm{ICH}$ ) or in both Broca's and Wernicke's areas (1 CLH and $1 \mathrm{ICH}$; no participants were RHem lateralized in only Wernicke's area).

A significant positive correlation was found between fMRI LI in Wernicke's area and DTI AFV LI in CLH only ( $r=.95, n=5, p=.01$; see Figures $7 \mathrm{a}, 7 \mathrm{~b}, 7 \mathrm{c})$. No other correlations obtained significance.

\section{Discussion}

The present study offers modest support that handedness direction and handedness degree both may be important to consider in examinations of AF asymmetry. Additionally, functional language lateralization may be related to some measures of AF asymmetry, particularly in individuals who are left hemisphere lateralized for language function.

Handedness can be conceptualized as varying along two dimensions: degree (consistent versus inconsistent) and direction (left versus right). These two dimensions are represented by different cortical areas (Dassonville, Zhu, Ugurbil, Kim, \& Ashe, 1997), with atypical functional language lateralization depending on both the direction, and degree, of handedness (Isaacs, Barr, Nelson, \& Devinsky, 2006; Khedr et al., 2001).

Here, we report that handedness modified arcuate fasciculus structure, such that $\mathrm{CRH}$ demonstrated larger AF volume in the left, relative to the right, hemisphere. Left hemisphere $\mathrm{AF}$ volume was larger than that of the right hemisphere in CLH, but this did not reach significance. However, the CLH did show a degree of asymmetry similar to that of CRH, and a very strong effect size (see Figures 3 and 6 b) but the variability was rather large; therefore, the small sample size and high variability may have resulted in the lack of significant difference between hemispheres in AF volume in this group. The ICH did not demonstrate either a marked asymmetry or a large effect size in hemispheric differences in AF volume (see Figures 3 and $6 c)$, suggesting no between hemisphere differences in this group. The pattern of effect sizes for AFV laterality scores (CRH versus ICH AFV $d=.78$; CLH versus ICH AFV $d=.54$; CRH versus CLH AFV $d=.35$ ) again suggests similarity between CLH and CRH, who both differ from the ICH. Future work could clarify the relationship between CLH and AF structure by recruiting a larger number of CLH individuals, but because only about 2-3\% of the population is consistently left-handed (Lansky, Feinstein, \& Peterson, 1988), this group is difficult to examine.

That there were no handedness group or hemispheric differences in AFL is confirmation that the tractography and segmentation methods performed as expected, such that tractography "fibers" of the same length in both hemispheres were measured in all groups, and that there was no systematic bias in tract length between handedness groups. Similarly, our arcuate fasciculate volumes are in line with previous work; we find that overall the right hemisphere's arcuate volume is $41 \%$ smaller than the left hemisphere's, a finding comparable to other findings of $36 \%$ (Matsumoto et al., 2008).

If our interpretation is correct - that is, leftward biased asymmetry for AF volume in consistently-handed individuals, regardless of the direction of hand preference, but relatively symmetric $\mathrm{AF}$ volume in $\mathrm{ICH}$ - then findings are comparable to other work demonstrating similarities between CLH and CRH, but between group differences as a function of degree of handedness (e.g.: Christman 1995; Barnett \& Corballis, 2002; Khedr et al., 2001; Niebauer, Aselage, \& Schutte, 2002; Propper, Christman, \& Phaneuf, 2005). 
This interpretation may also shed light on the findings of Vernooij et al. (2007), who reported leftward AF asymmetry regardless of handedness: more than three times as many non-righthanders in Vernooij et al's sample were CLH $(n=10)$ compared to ICH $(n=3)$, possibly biasing that group to demonstrate an AF asymmetry. Thus, it may be that hand preference categorization in part resulted in Vernooij et al.'s finding of no between group handedness differences in AF structure.

It is noteworthy that the present findings for volume of the AF are similar to those of Hagmann et al. (2006), who reported decreased asymmetry of the AF in non-right-handed men and in women; calculation of the mean EHI scores in that study indicates that Hagmann et al. may have compared CRH with ICH. Again, given the dissimilarities noted previously between consistent- and inconsistent-handers, and in the context of conceptualizing hand preference along degree, rather than direction, differences between these groups would be expected.

We find no relationship between measures of the arcuate fasciculus and fMRI language lateralization in either Broca's or Wernicke's areas. The elimination of four participants who demonstrated right hemisphere language lateralization did result in a positive relationship. We partially replicated Vernooij et al. (2007) in that we report a positive relationship between a measure of the AF (volume) and activation in Wernicke's area in individuals with varying degrees of left hemisphere functional language lateralization. However, while this relationship was reported as being in RH in the former study, here such relationship occurred only in the CLH group. Interestingly, in Vernooij et al., 6 of the $13 \mathrm{LH}$ were RHem lateralized for language, while none of the RH were. This raises the possibility that in the former study, the lack of a relationship between activation in Wernicke's area and AF asymmetry in LH may reflect the fact that these individuals were mostly RHem language lateralized. Why right hemisphere language lateralization might result in altered structure-function relationships is unclear, but warrants further investigation, particularly given that in the current study this relationship was found with an $n$ of only 5 individuals, which leaves open the question of whether these findings are more apparent than real.

The present results offer some support that hand preference may be a useful indicator of anomalous structural and functional language organization in pre-operational settings. Specifically, handedness degree, in addition to direction (Schacter, 1994), may be particularly worth noting in pre-operative settings in order to ensure full evaluation of language structures and functions, although the use of AF measures as an indicator of language lateralization needs further investigation. Given that in the present research arcuate fasciculus volume was affected by handedness degree, in conjunction with other work showing an effect if handedness direction on language related structures (e.g.: Foundas, Eure, Luevano, \& Weinberger, 1998) future research should make an effort to control for both direction and degree of hand preference. At the very least, in addition to allowing for detection of small between group differences that may be obscured when ICH are categorized with CLH, standardization of handedness measures would allow for between-study comparisons of the effects of hand preference on structural and functional dependent measures.

\section{Acknowledgments}

Support for this research was provided by NIH grants: NINDS, K08-NS048063-02 (AJG); NCRR, U41-RR019703 (AJG); and R25 CA089017-06A2 (LO) and the Brain Science Foundation (AJG). The authors would like to thank Stephen D. Christman, Ph.D., at the University of Toledo, Psychology Department, Toledo, Ohio, for comments and suggestions. 


\section{References}

American Psychological Association. Publication Manual of the American Psychological Association. 5th Edition. Vol. 5. Washington, DC: APA; 2001. p. 25-26.

Barnett KJ, Corballis MC. Ambidexterity and magical ideation. Laterality 2002;7:75-84. [PubMed: 15513189]

Basser PJ, Pajevic S, Pierpaoli C, Duda J, Aldroubi A. In vivo fiber tractography using DT-MRI data. Magnetic Resonance in Medicine 2000;44:625-632. [PubMed: 11025519]

Branco DM, Suarez RO, Whalen S, O'Shea JP, Nelson AP, da Costa JC, Golby AJ. Functional MRI of memory in the hippocampus: Laterality indices maybe more meaningful if calculated from whole voxel distributions. Neuroimage 2006;1532:592-602. [PubMed: 16777435]

Brunye, Mahoney CR, Augustyn JS, Taylor HA. Horizontal saccadic eye movements enhance the retrieval of landmark shape and location information. Brain and Cognition. In press.

Cabeza R, Nyberg L. Imaging cognition II: an empirical review of 275 PET and fMRI studies. Journal of Cognitive Neuroscience 2000;12:1-47. [PubMed: 10769304]

Catini M, Allin MP, Husain M, Pugliese L, Mesulam MM, Murray RM, Jones DK. Symmetries in human brain language pathways correlate with verbal recall. Proceedings of the National Academies of Science USA 2007;104:17163-17168.

Christman S. Handedness in musicians: Bimanual constraints on performance. Brain and Cognition 1995;22:266-272. [PubMed: 8373577]

Corballis MC. From mouth to hand: Gesture, speech, and the evolution of right-handedness. Behavioral Brain Sciences 2003;26:199-260.

Dassonville P, Zhu X-H, Ugurbil K, Kim S-G, Ashe J. Functional activation in motor cortex reflects the direction and the degree of handedness. Proceedings of the National Academy of Sciences 1997;94:14015-14018.

Dorsaint-Pierre R, Penhune VB, Watkins KE, Neelin P, Lerch JP, Bouffard M, Zatorre RJ. Asymmetries of the planum temporale and Heschl's gyrus: Relationship to language lateralization. Brain 2006;129:1164-1176. [PubMed: 16537567]

Dronkers, NF.; Larsen, J. Neuroanatomy of the classical syndromes of aphasia. In: Berndt, RS., editor. Handbook of neuropsychology, 2nd ed.: Language and aphasia. Amsterdam: Elsevier; 2001. p. 19-30.

Foundas AL, Eure KF, Luevano LF, Weinberger DR. MRI asymmetries of Broca's area: The pars triangularis and pars opercularis. Brain and Language 1998;64:282-296. [PubMed: 9743543]

Foundas AL, Leonard CM, Gilmore RL, Fennell EB, Heilman KM. Pars triangularis asymmetry and language dominance. Proceedings of the National Academy of Sciences 1996;26:719-722.

Friston KJ, Holmes AP, Worsley KJ, Poline J-P, Frith CD, Frackowiak RSJ. Statistical parametric maps in functional imaging: A general linear approach. Human Brain Mapping 1995;2:189-210.

Gazzaniga MS. Cerebral specialization and interhemispheric communication: Does the corpus callosum enable the human condition? Brain 2000;123:1293-1326. [PubMed: 10869045]

Hagmann P, Cammoun L, Martuzzi R, Maeder P, Clarke S, Thiran J-P, Meuli R. Hand preference and sex shape the architecture of language networks. Human Brain Mapping 2006;27:828-835. [PubMed: $16541458]$

Hellige, JB. Hemispheric asymmetry: What's right and what's left. Boston MA: Harvard University Press; 2001.

Isaacs KL, Barr WB, Nelson PK, Devinsky O. Degree of handedness and cerebral dominance. Neurology 2006;66:1855-1858. [PubMed: 16801650]

Jansen A, Menke R, Sommer J, Forster AF, Bruchmann S, Hempleman J, Weber B, Knecht S. The assessment of hemispheric lateralization in functional MRI--robustness and reproducibility. Neuroimage 2006;33:204-217. [PubMed: 16904913]

Khedr EM, Hamed E, Said A, Basahi J. Handedness and language cerebral lateralization. European Journal of Applied Physiology 2002;87:469-472. [PubMed: 12172889]

Knecht S, Deppe M, Dräger B, Bobe L, Lohmann H, Ringelstein E, Henningsen H. Language lateralization in healthy right-handers. Brain 2000a;123:74-81. [PubMed: 10611122] 
Knecht S, Dräger B, Deppe M, Bobe L, Lohmann H, Flöel A, Ringelstein E-B, Henningsen H. Handedness and hemispheric language dominance in healthy humans. Brain 2000b;123:2512-2518. [PubMed: 11099452]

Laland KN, Kumm J, Van Horn JD, Feldman MW. A gene-culure model of handedness. Behavioral Genetics 1995;25:433-445.

Lansky LM, Feinstein H, Peterson JM. Demography of handedness in two samples of randomly selected adults ( $=2083)$. Neuropsychologia 1988;26:465-477. [PubMed: 3374805]

Lyle KB, Logan JM, Roediger HL III. Eye movements enhance memory for individuals who are strongly right-handed and harm it for individuals who are not. Psychonomic Bulletin and Review 2008;15:515-520. [PubMed: 18567248]

Matsumoto R, Okada T, Mikuni N, Mitsueda-Ono T, Taki J, Sawamoto N, Hanakawa T, Miki Y, Hashimoto N, Fukuyama H, Takahashi R, Ikeda A. Hemispheric asymmetry of the arcuate fasciculus. Journal of Neurology 2008;255:1703-1711. [PubMed: 18821045]

McManus, IC.; Bryden, MP. The genetics of handedness, cerebral dominance and lateralization. In: Rapin, I.; Segalowitz, SJ., editors. Handbook of neuropsychology: Sec 10, Developmental Neuropsychology. Amsterdam: Elsevier; 1992. p. 115-144.

Moffat SD, Hampson E, Lee DH. Morphology of the planum temporale and corpus callosum in lefthanders with evidence of left and right hemisphere speech representation. Brain 1998;121:2369_ 2379. [PubMed: 9874487]

Niebauer CL, Aselage J, Schutte C. Hemispheric interaction and consciousness: Degree of handedness predicts the intensity of a sensory illusion. Laterality 2002;7:85-96. [PubMed: 15513190]

Nucifora PGP, Verma R, Melhem ER, Gur RE, Gur RC. Leftward asymmetry in relative fiber density of the arcuate fasciculus. Neuroreport 2005;16:791-795. [PubMed: 15891571]

O'Donnell L, Westin C-F. Automatic Tractography Segmentation Using a High-Dimensional White Matter Atlas. IEEE Transactions in Medical Imaging 2007;26:1562-1575.

O'Donnell L, Westin C-F, Golby A. Tract-based morphometry for white matter group analysis. NeuroImage 2009;45:832-844. [PubMed: 19154790]

Oldfield R. The assessment and analysis of handedness: The Edinburgh Inventory. Neuropsychology 1971;9:97-113.

Papathanassiou D, Etard O, Mellet E, Zago B, Mazoyer B, Tzourio-Mazoyer N. A common language network for comprehension and production: A contribution to the definition of language epicenters with PET. Neuroimage 2000;11:347-357. [PubMed: 10725191]

Parker GJM, Luzzi S, Alexander DC, Wheeler-Kingshott CAM, Ciccarelli O, Ralph MAL. Lateralization of ventral and dorsal auditory-language pathways in the human brain. Neuroimage 2006;24:656666. [PubMed: 15652301]

Pierpaoli C, Jezzard P, Basser PJ, Barnett A, Di Chiro G. Diffusion tensor MR imaging of the human brain. Radiology 1996;201:637-648. [PubMed: 8939209]

Powell HW, Parker GJM, Alexander DC, Symms MR, Boulby PA, Wheeler-Kingshott CAM, Barker GJ, Noppeney U, Koepp MJ, Duncan JS. Hemispheric asymmetries in language-related pathways: A combined functional MRI and tractography study. Neuroimage 2006;32:388-399. [PubMed: 16632380]

Propper RE, Christman SD, Phaneuf KA. A mixed-handed advantage in episodic memory: A possible role of interhemispheric interaction. Memory and Cognition 2005;33:751-757.

Schacter SC. Ambilaterality:Definition from handedness preference questionnaires and potential significance. International Journal of Neuroscience 1994;77:47-51. [PubMed: 7989160]

Shapleske J, Rossell SL, Woodruff PWR, David AS. The planum temporale: A systematic, quantitative review of its structural, functional and clinical significance. Brain Research Review 1999;29:26-49.

Suarez RO, Whalen S, Nelson AP, Tie Y, Meadows M-E, Radmanesh A, Golby AJ. Thresholdindependent functional MRI determination of language dominance: A validation study against clinical gold standards. Epilepsy \& Behavior. In Press.

Suarez RO, Whalen S, O'Shea JP, Golby AJ. A surgical planning method for functional MRI assessment of language dominance: influences from threshold, region-of-interest, and stimulus mode. Brain Imaging and Behavior. 2008 
Szaflarski JP, Binder JR, Possing ET, McKiernan KA, Ward BD, Hammeke TA. Language lateralization in left-handed and ambidextrous people: FMRI data. Neurology 2002;59:238-244. [PubMed: 12136064]

Valentine, JC.; Cooper, H. Effect size substantive interpretations guidelines: Issues in the interpretation of effect sizes. Washington DC: What Works Clearinghouse; 2003.

Vernooij MW, Smits M, Wielopolski PA, Houston GC, Krestin GP, van der Lugt A. Fiber density asymmetry of the arcuate fasciculus in relation to functional hemispheric language lateralization in both right and left handed healthy subjects: a combined fMRI and DTI study. Neuroimage 2007;35:1064-1076. [PubMed: 17320414]

Westin C-F, Maier SE, Mamata H, Nabavi A, Jolesz FA, Kikinis R. Processing and visualization for diffusion tensor MRI. Medical Image Anaysis 2002;6:93-108.

Zöllei L, Learned-Miller EG, Grimson WEL, Wells WM. Efficient Population Registration of 3D Data. CVBIA 2005:291-301. 


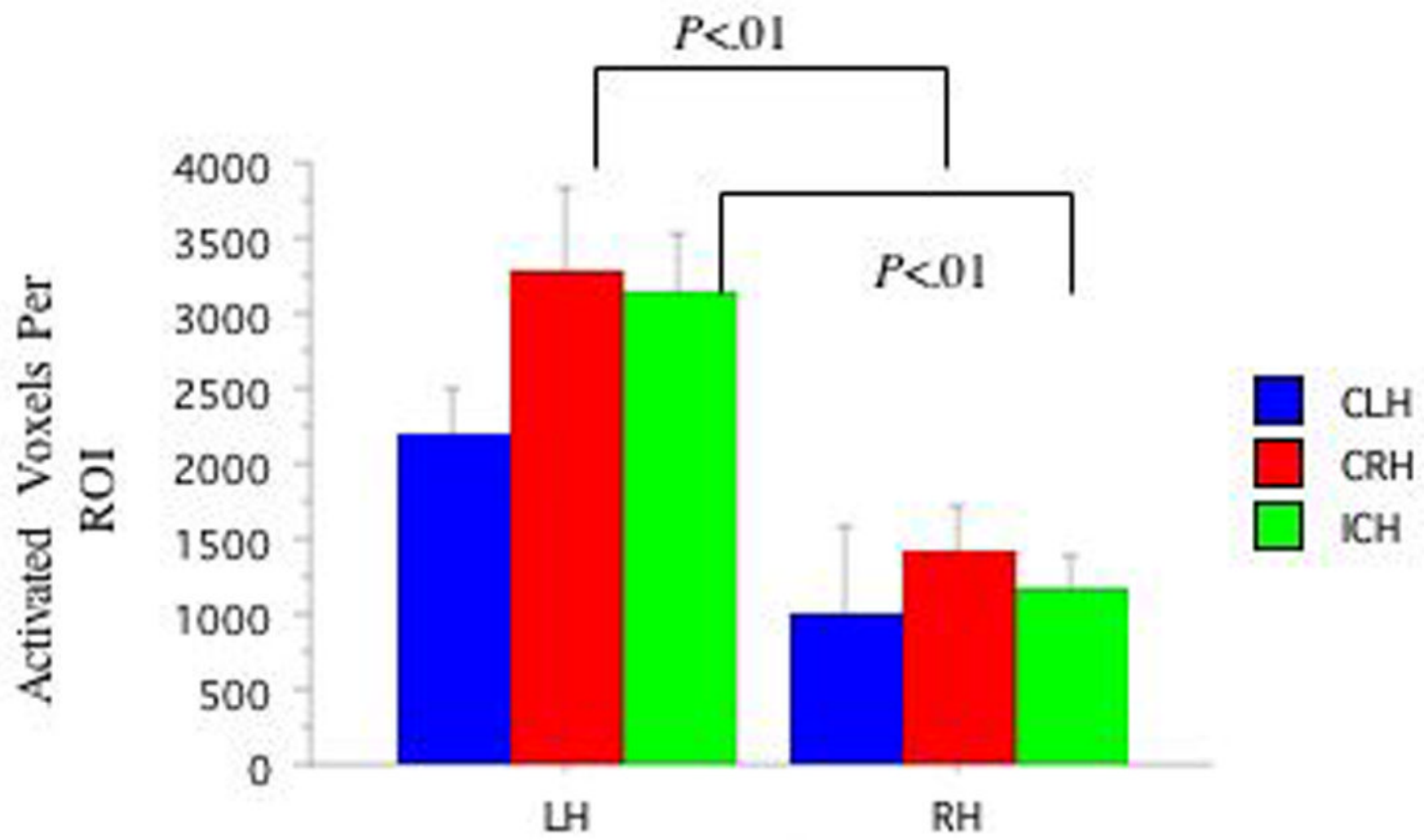

\section{Hemisphere}

Figure 1. FMRI Activation in Broca's and Right Hemisphere Homolog Areas as a Function of Handedness Group 


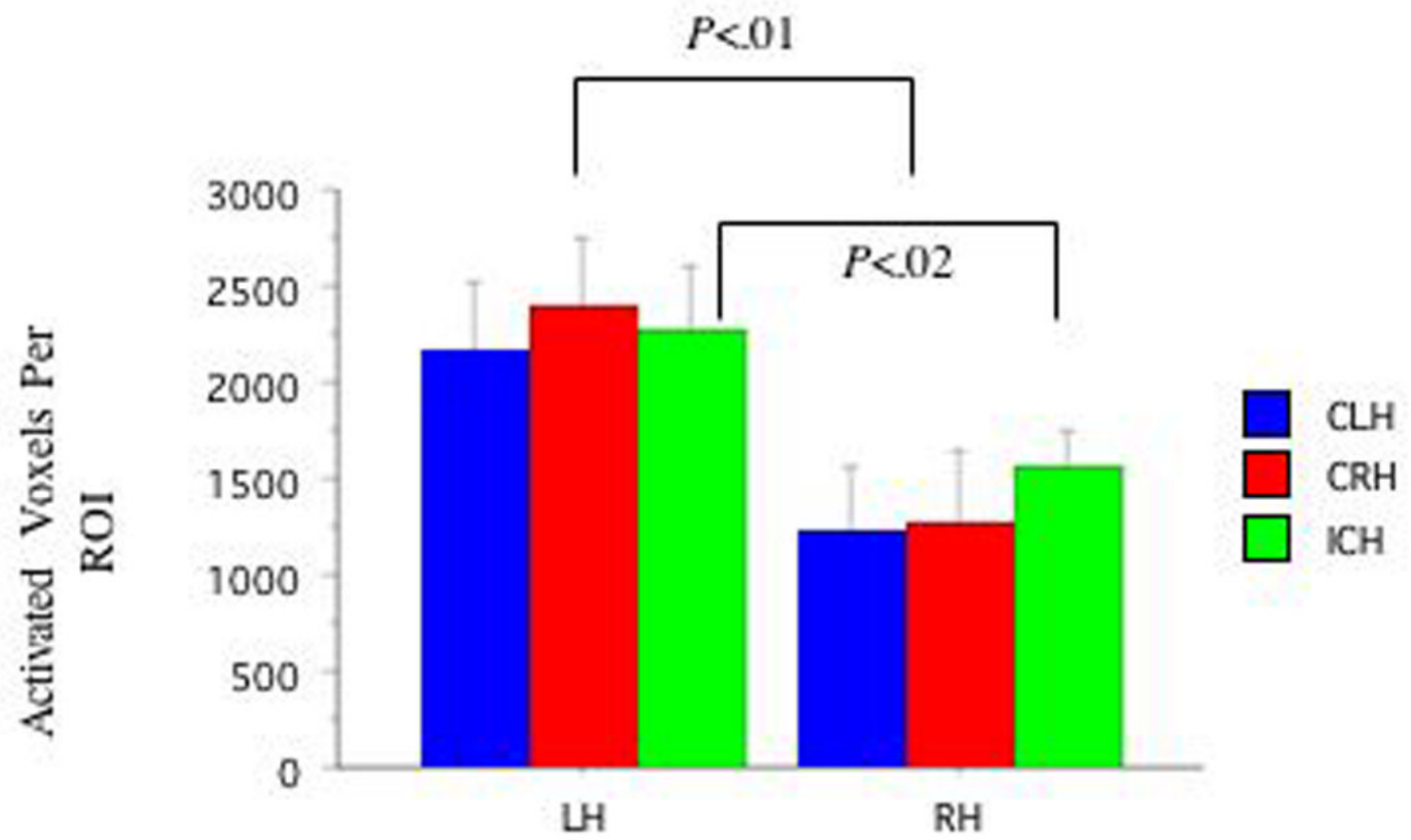

Hemisphere

Figure 2. FMRI Activation in Wernicke's and Right Hemisphere Homolog Areas as a Function of Handedness 


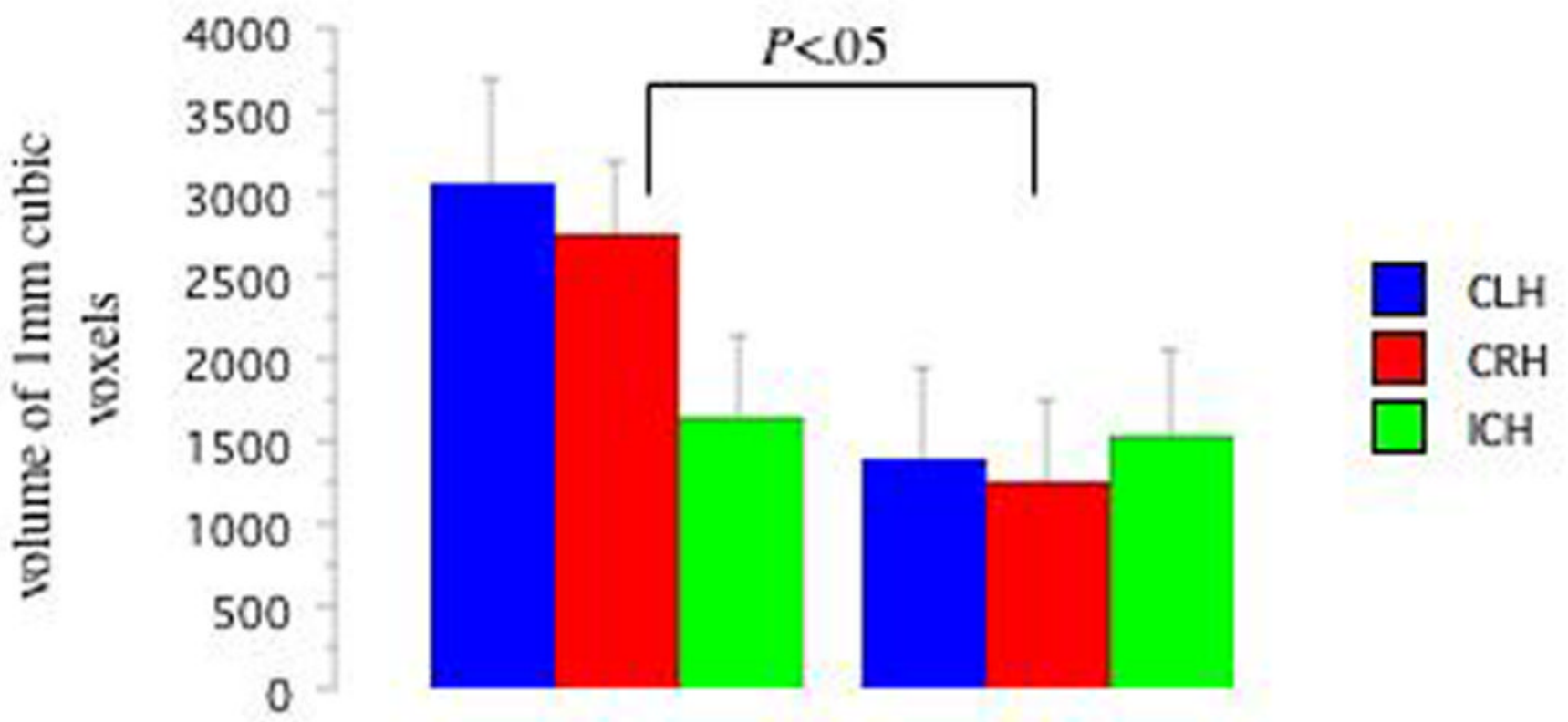

\section{Hemisphere}

Figure 3. DTI AFV as a Function of Handedness Group and Hemisphere 


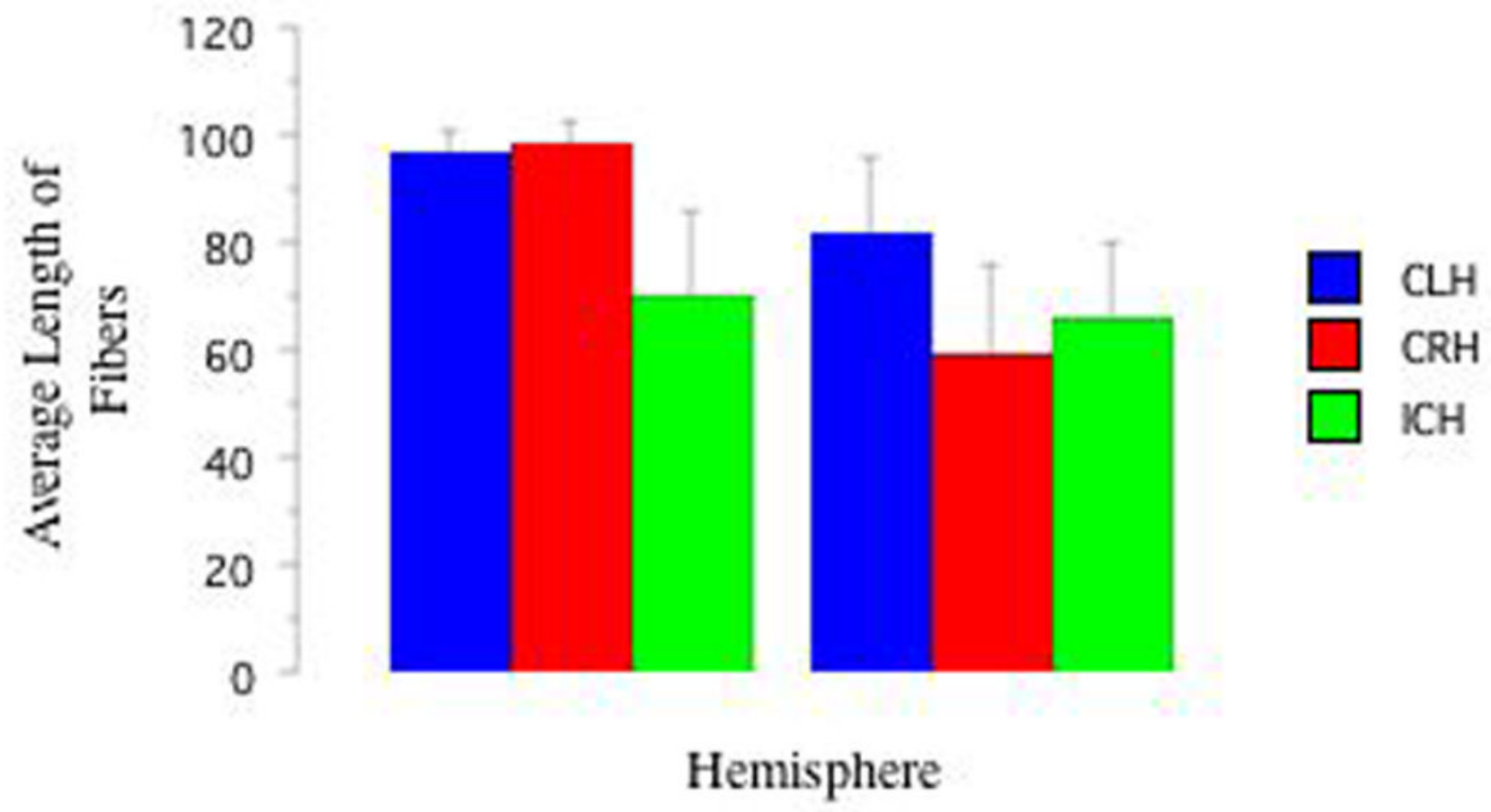

Figure 4. DTI AFL as a Function of Handedness Group and Hemisphere 

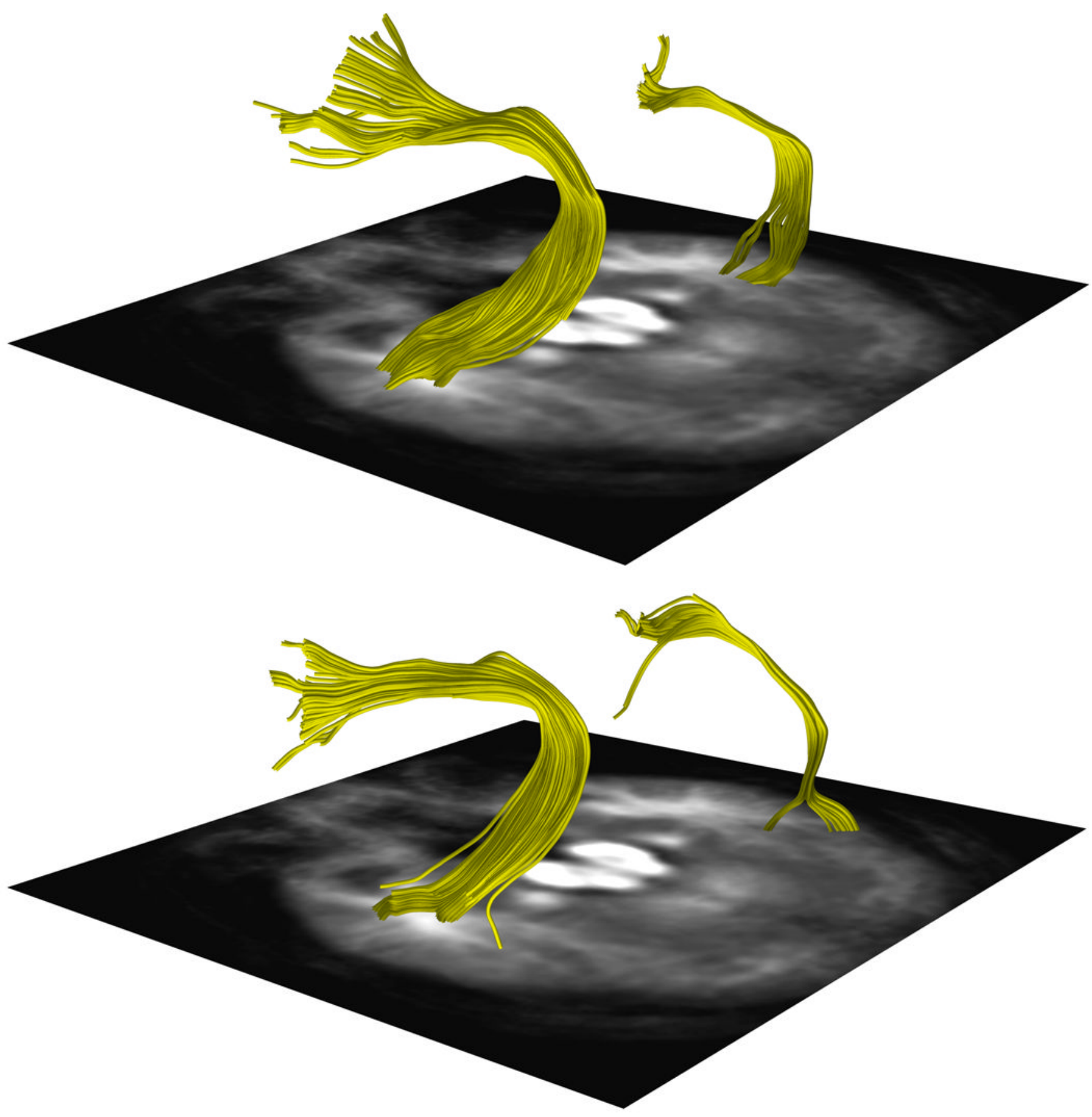

Brain Cogn. Author manuscript; available in PMC 2011 July 1. 


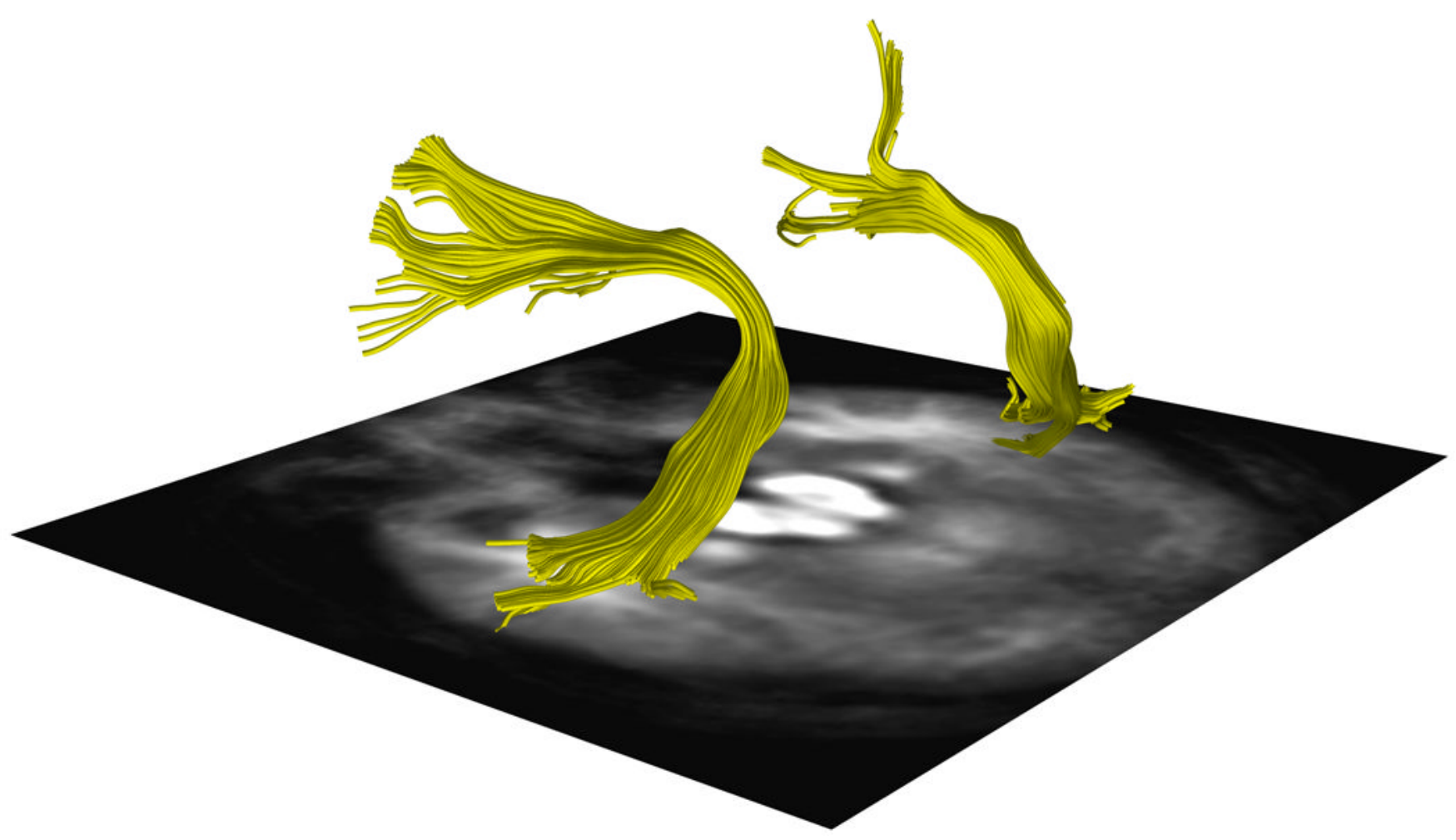

Figure 5. Arcuate Fasciculus Tractography from One Subject Per Handedness Group $\mathrm{a}, 5 \mathrm{~b}$ and $5 \mathrm{c}$. DTI images show a representative AF traced from one subject in the a.CRH, b.CLH, and c.ICH groups. 


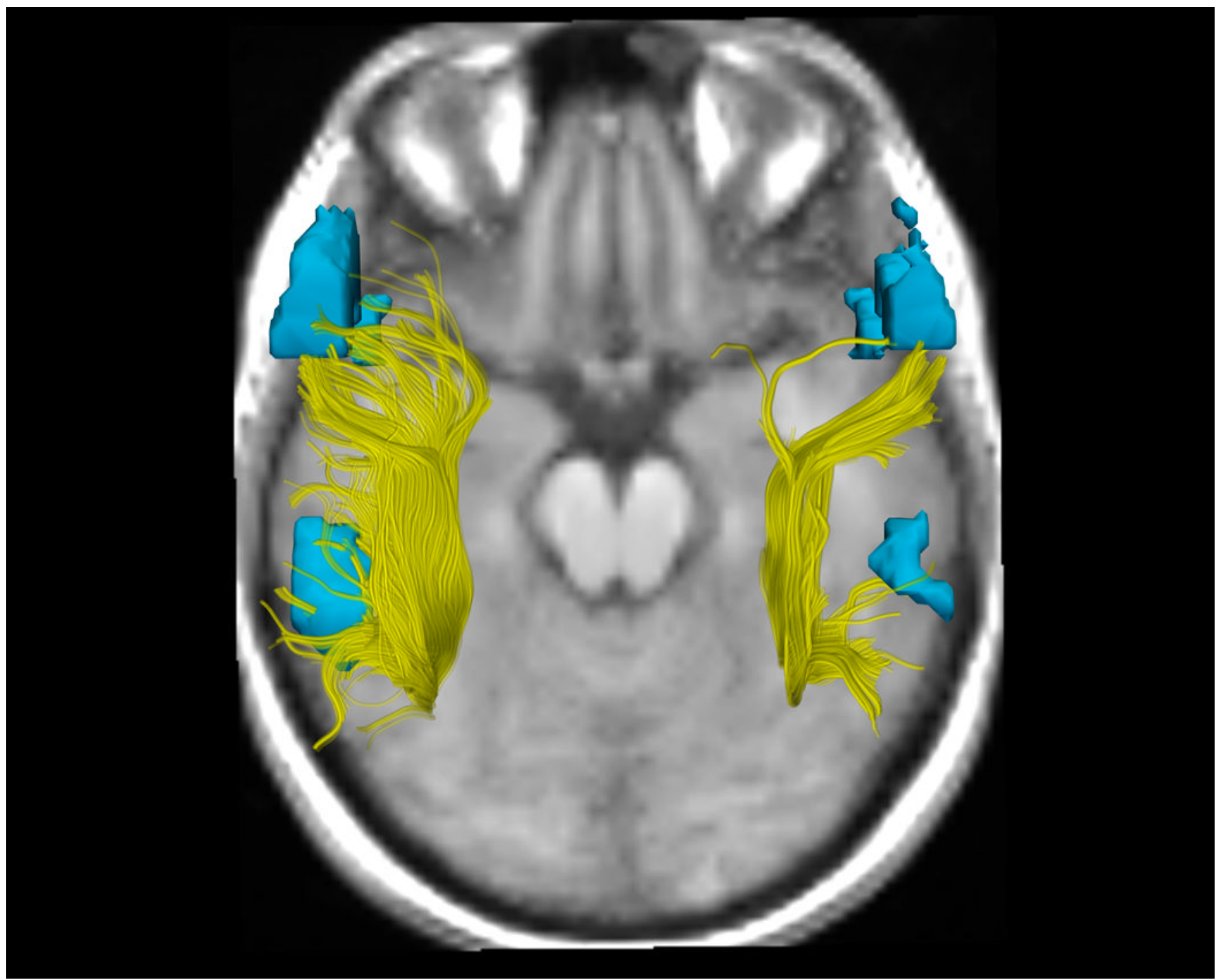

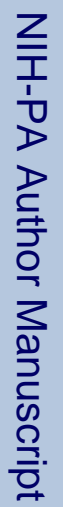




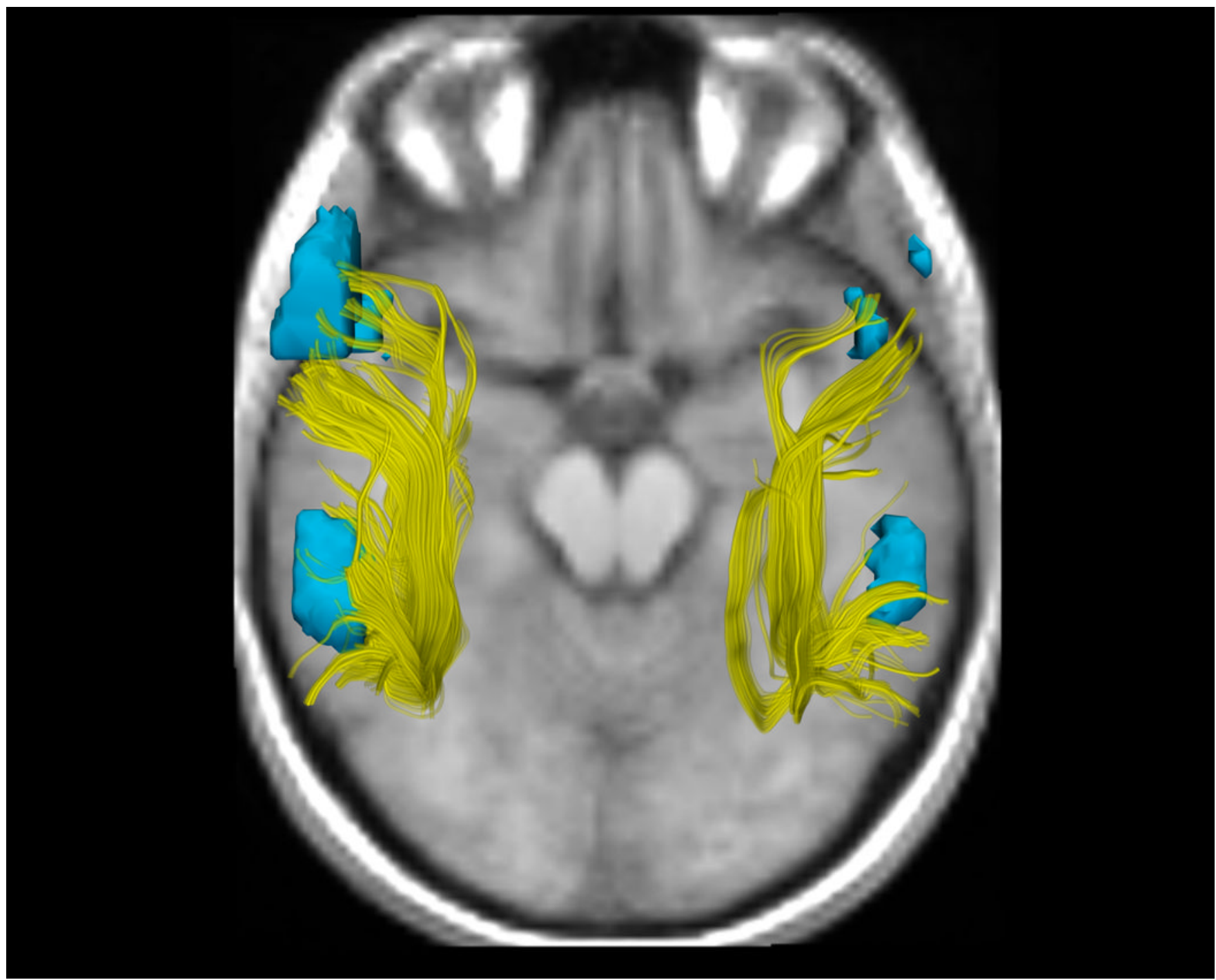

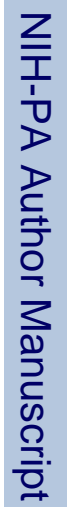




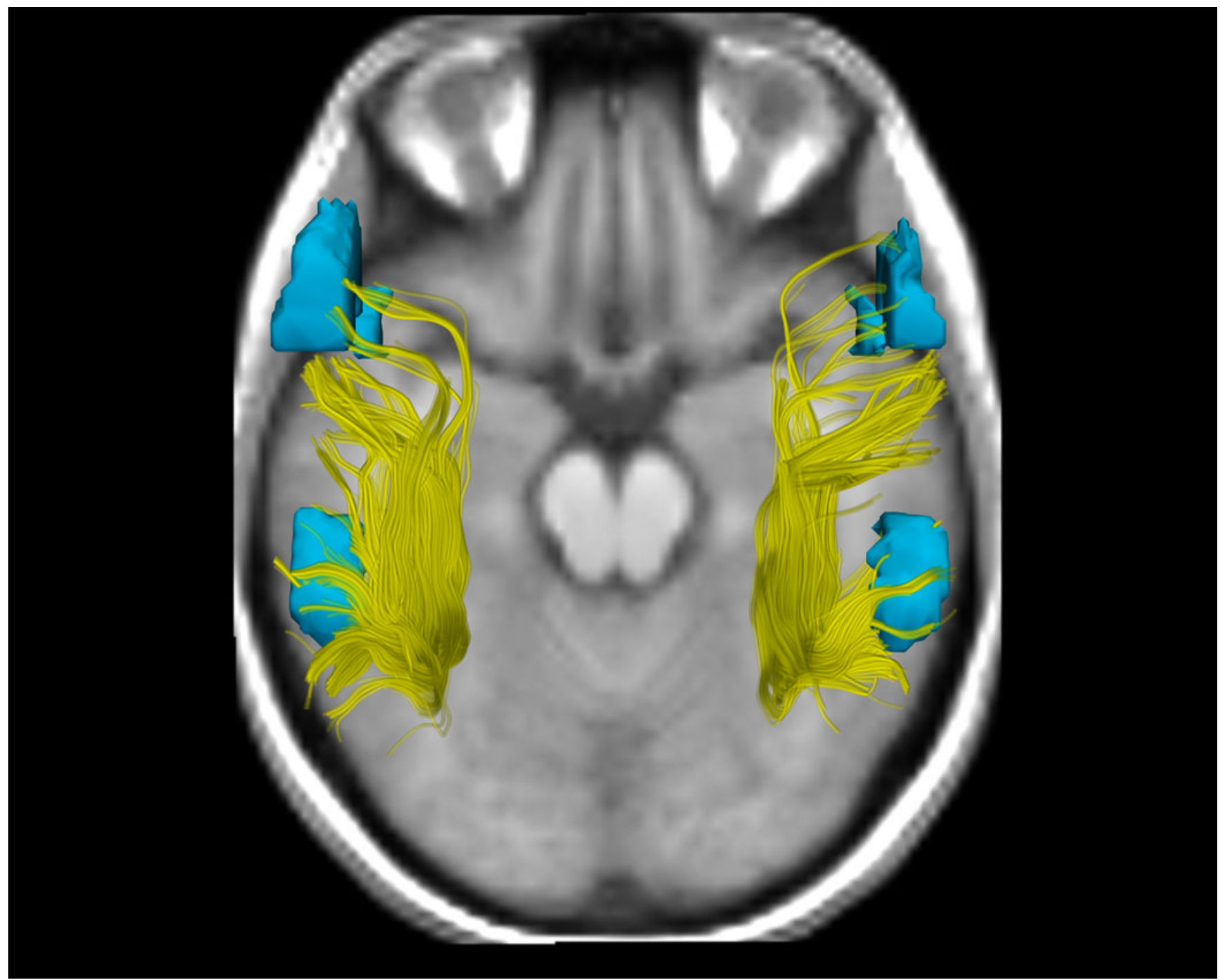

Figure. Arcuate Fasciculus Structure and Functional Language Activation in the Putative Language Areas as a Function of Handedness Group

$6 \mathrm{a}, 6 \mathrm{~b}$, and $6 \mathrm{c}$. DTI and fMRI analyses show differences in functional and structural asymmetry across groups (a. CRH, b. CLH, c. ICH). DTI tractography in the AF in the right and left hemispheres, showing all fibers from all subjects in each group, is displayed in yellow. fMRI activations from an antonym generation task, rendered as 3D surface models of thresholded activation maps for each group (Thresholds: $\mathrm{p}<.05$ ), indicate the putative language areas of Broca's and Wernicke's areas in the left hemisphere, and their homologous activations in the right hemisphere. To most clearly show the AF, the viewpoint for all images is superior (viewed from above), consequently the subjects' left is on the left side of the image. The background image was chosen to give anatomical context without overlapping the fibers or fMRI, and shows each group mean SPGR image at a location inferior to the AF and activations. 


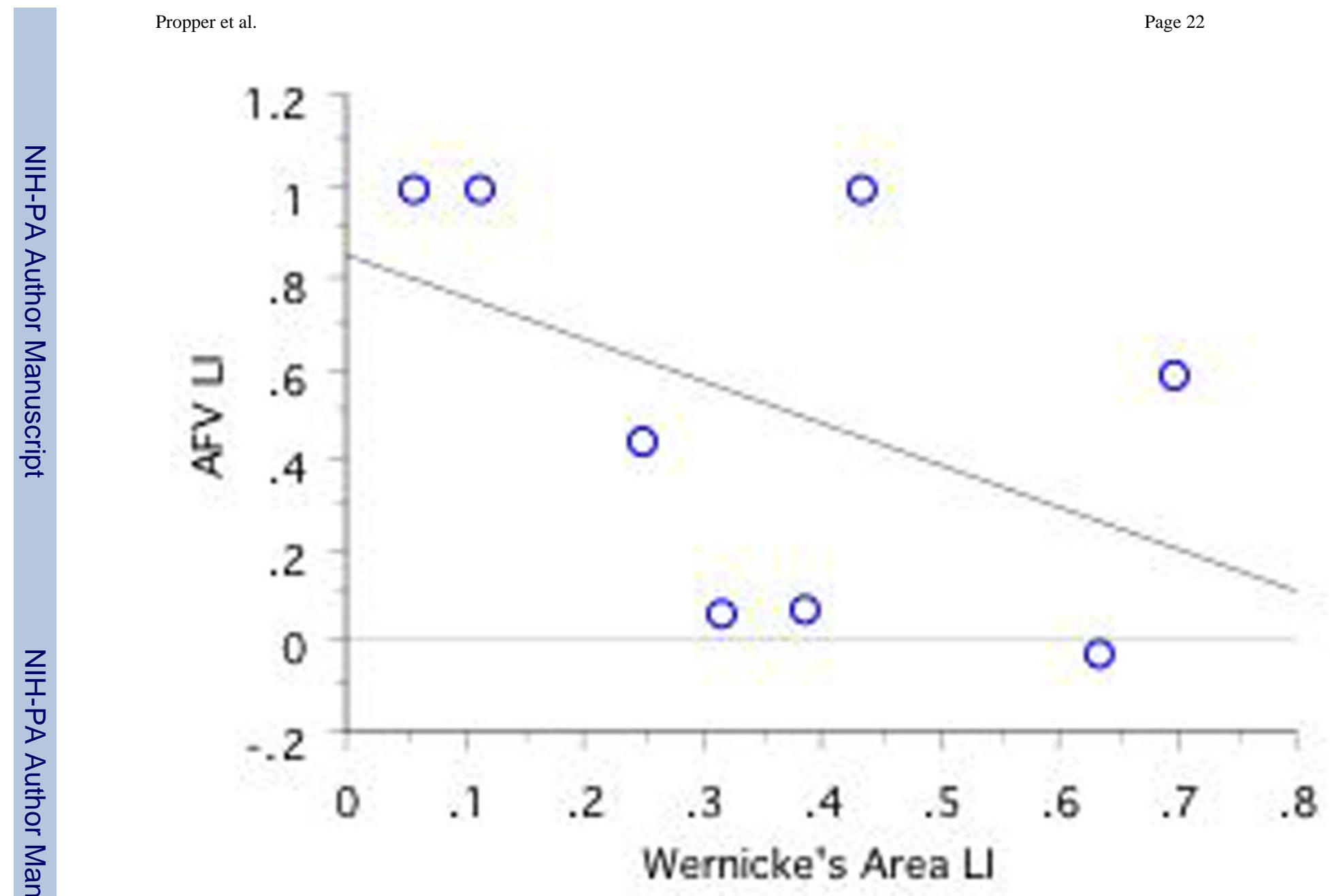




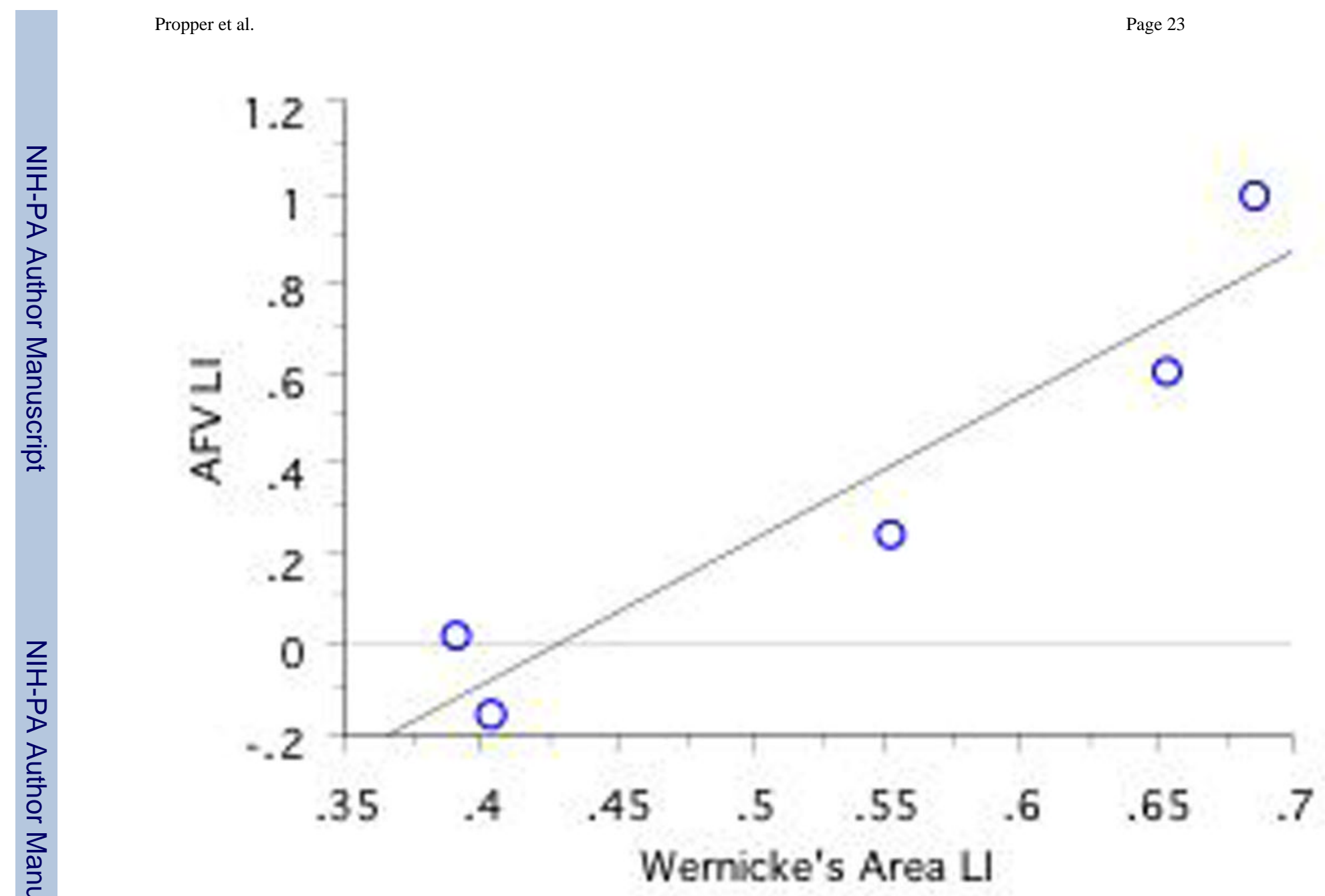




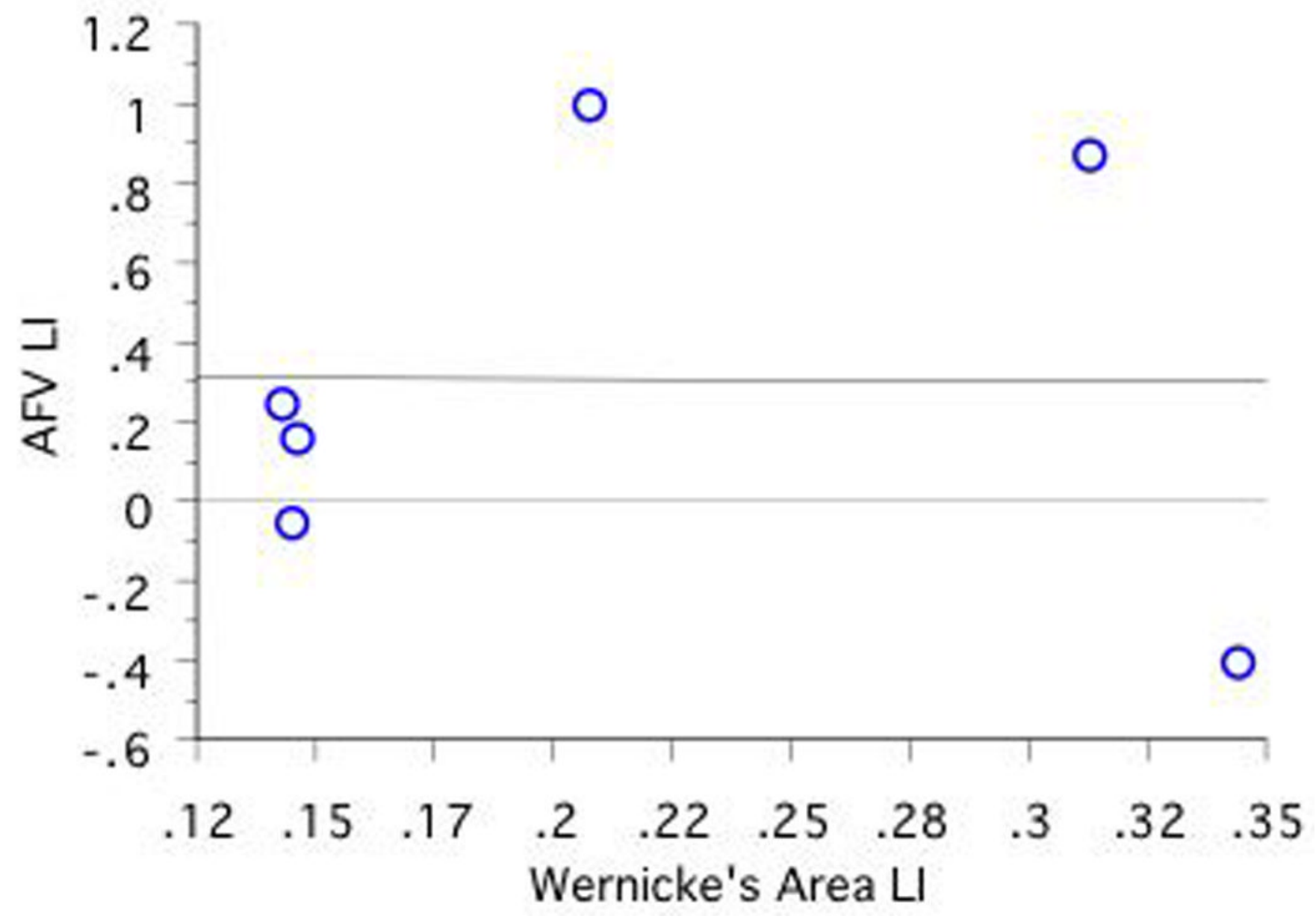

Figure 7. Correlations Between Language Lateralization in Wernicke's Area and AFV Lateralization as a Function of CRH, CLH, and ICH Group. Note that RHem language lateralized individuals are excluded

a, $7 \mathrm{~b}$, and $7 \mathrm{c}$ 


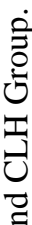

苞

王

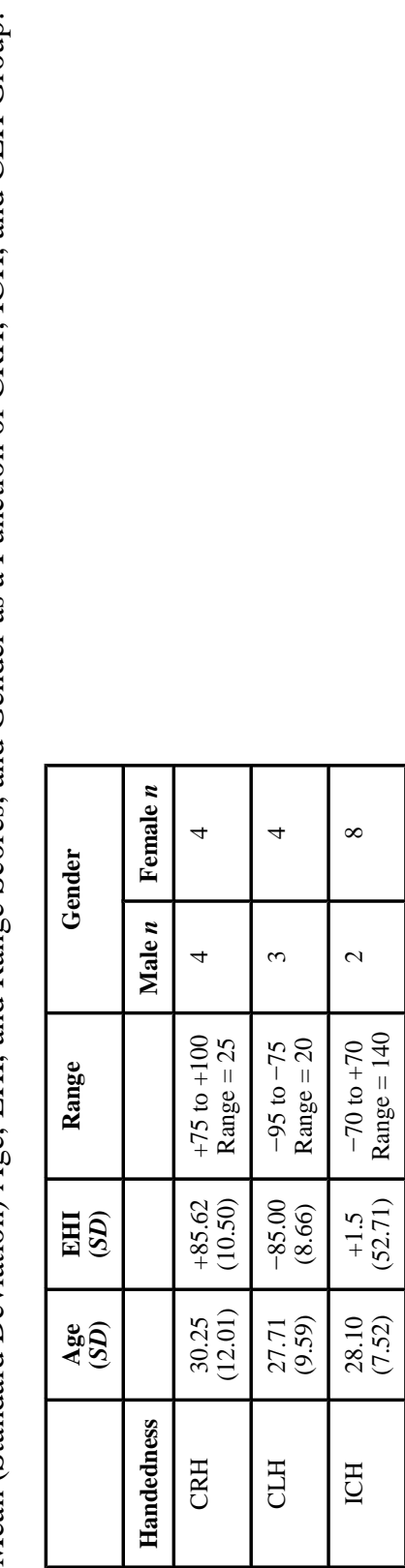

Brain Cogn. Author manuscript; available in PMC 2011 July 1. 
Table 2

Mean (Standard Error) Laterality Scores for FMRI and DTI Measures as a Function of CRH, CLH, and ICH Group.

\begin{tabular}{|l|c|c|c|c|}
\hline & \multicolumn{4}{|c|}{ Group } \\
\hline ROI & CRH & CLH & ICH & All Subjects \\
\hline Broca's LI & $.42(.07)$ & $.52(.21)$ & $.47(.09)$ & $.47(.07)$ \\
\hline Wernicke's LI & $.36(.08)$ & $.29(.17)$ & $.17(.06)$ & $.26(.06)$ \\
\hline AFV LI & $.52(.16)$ & $.37(.14)$ & $.08(.23)$ & $.32(.11)$ \\
\hline AFL LI & $.38(.18)$ & $.14(.14)$ & $.03(.19)$ & $.19(.10)$ \\
\hline
\end{tabular}

